\title{
Romeu e Julieta no cinema brasileiro: adaptações, apropriações e intertextos
}

Marcel Vieira Barreto Silva

\section{Resumo}

Este artigo busca investigar as várias formas de apropriação da peça Romeu e Julieta (1595-1596), do dramaturgo inglês William Shakespeare, no cinema brasileiro. Os filmes, seja ao apropriar uma ou mais cenas, seja ao compor sua história a partir da trama da peça, colocam o texto shakespeariano em permanente tensão de significado com os contextos e os gêneros em que os filmes se inserem. Nesse sentido, pretendemos investigar o modo como esses filmes re-inventam a história de Romeu e Julieta, enfatizando a maneira como cada qual se esforça para criar novas formas de expressão do tema shakespeariano, a partir do diálogo com a comédia popular, o musical e o drama urbano no Brasil. Palavras-chave

Shakespeare no cinema. Adaptação cinematográfica. Cinema brasileiro.
Marcel Vieira Barreto Silva I marcelvbs@hotmail.com

Universidade Federal Fluminense. Aluno do doutorado do Programa de Pós-graduação em Comunicação da Universidade Federal Fluminense, com projeto de tese intitulado "A presença de Shakespeare no Cinema Brasileiro". Autor da dissertação de mestrado intitualdo "Entre mimese e diegese: a construção da cena na adaptação de Closer", com orientação do Prof. Dr. João Luiz Vieira, na UFF.

\section{Introdução: a ubiquidade de Shakespeare}

Em um episódio do programa Os Trapalhões, exibido em 1986, pela Rede Globo, um dos esquetes é uma paródia da famosa cena do balcão da peça Romeu e Julieta (1595-1596), de William Shakespeare. No início da cena, a cantora de Jovem Guarda Rosemary, no papel de Julieta, está em primeiro plano, na sacada de um suposto palácio - nitidamente construído em estúdio -, pintado de rosa bem chamativo e com detalhes amarelos. Ela traja um vestido que remete ao tempo medieval e tem os cabelos loiros amarados numa longa trança. 0 som de um alaúde toca o tema A time for us, composto por Henry Mancini para o filme Romeu e Julieta (1968), de Franco Zeffirelli. Após um zoom out, surge ao pé da sacada Renato Aragão, vestido de roupas medievais carnavalescamente coloridas, no papel de Romeu, e Dedé Santana, com vestimenta semelhante, como um amigo. 0 alaúde está sendo tocado por Romeu que, com as tradicionais feições cômicas de Aragão, acompanha com a voz: "A time for us, a time for us... Chivas, Ballantines, Old Eight, Smirnoff...". 
Logo em seguida, o som do tema de Mancini é sobreposto pelo famoso solo inicial de Brasileirinho, choro composto em 1947, por Waldir Azevedo, e que é costumeiramente associado à nossa identidade musical. A sequência do esquete é uma série de patacoadas, em que Romeu, com a necessidade de convencer o velho Capuleto de que é um homem justo para se casar com Julieta, é enganado por Mercúcio (interpretado por Zacarias), ocasionando os trocadilhos e quiproquós característicos d'Os Trapalhões.

Ao encenar o tema de Romeu e Julieta, através da atualização cômica do programa televisivo, 0 episódio supracitado constrói um envolvimento expressivo de vários meios: 0 teatro elisabetano, o esquete cômico televisivo, a música popular e mesmo o cinema (que surge através do tema do filme de Zeffirelli). Tal procedimento de apropriação consiste em misturar essas diversas retóricas, criando um amálgama de referências que insere inúmeras camadas de significado na matriz shakespeariana que lhe serviu de fonte. Além disso, ao sobrepor A time for us com Brasileirinho, identificamos um processo de contextualização do tema shakespeariano no ambiente cultural do país - procedimento esse que, conforme veremos ao longo deste artigo, caracteriza as várias apropriações de Romeu e Julieta pelo cinema brasileiro.

Devemos enfatizar, ainda, que essas formas de apropriação estão relacionadas diretamente com a circulação de um imaginário imagético em torno de Romeu e Julieta, que transcende a mera análise comparativa entre texto-fonte e filme. Há registros, por exemplo, de filmes curtos da peça já em 1901, numa versão de George Méliès. Durante toda a primeira década do século XX, diversas fitas surgiram, de companhias como a Pathé, a Vitagraph e a Film d'Arte Italiana. Versões mais longas da peça começaram a surgir já em 1916, com fitas da MGM e da Fox (essa última com 70 min. e a estrela Theda Bara como Julieta), até a chegada do cinema falado e a versão de George Cukor, superprodução de Irving Thalberg para MGM, que, apesar de seu enorme fracasso comercial, contribui para associar Shakespeare ao star system hollywoodiano.

A grande questão envolvendo Shakespeare e 0 cinema silencioso é, precisamente, a ausência dos diálogos (e, desta forma, da poesia verbal shakespeariana), que deve, portanto, ser compensada por uma imagética que possa tanto contar a história, quanto transmitir a subjetividade dos personagens (algo que, na peça, fica a cargo da palavra). Esse desafio possibilitou a criação de uma imagética em torno de Romeu e Julieta, pois os filmes eram curtos e tinham que sintetizar a trama em algumas cenas paradigmáticas. Essa imagética shakespeariana entra em circuito com a circulação das fitas pelos diversos países, formando um imaginário que ajuda a construir 0 modo como cineastas não anglófonos se apropriam de Shakespeare, menos talvez de seu texto e mais das imagens produzidas em torno dele. 


\section{Nem Romeu nem Julieta: atualizações paródicas do tema shakespeariano}

A primeira aparição de Shakespeare no cinema brasileiro parece ter sido o filme curto (hoje perdido) Romeu e Julieta, capturado em 35 mm, em preto e branco, e realizado em 1923, no Rio de Janeiro (então, capital federal). Produzido, dirigido e encenado por Generoso Ponce, o filme, segundo consta nos documentos da Cinemateca Brasileira, seria uma paródia da cena do balcão, co-atuada com a esposa do diretor. Esse tipo de adaptação de cenas famosas da literatura representou uma importante maneira de 0 cinema alcançar o prestígio das artes consagradas para, com isso, ter acesso a plateias para quem o teatro de Shakespeare representava um dos ápices da cultura do letramento. Como indica F. Silva Nobre (1964, p. 20), "quando as vistas cinematográficas constituíam espetáculos sem expressão, agradando apenas pelo prazer da novidade, 0 recurso às suas obras [de Shakespeare] indicou rumo certo aos produtores, redobrando a atenção e 0 entusiasmo das plateias".

No caso brasileiro, embora o filme esteja perdido, as referências a ele, inclusive, na Enciclopédia do Cinema Brasileiro (MIRANDA; RAMOS, 2000, p. 161), constam que seja uma paródia. É interessante perceber, historicamente, como a cena do balcão será reinventada, parodicamente, mais de vinte anos depois do filme de Generoso Ponce. Em
1949, no filme Carnaval no fogo, de Watson Macedo, Oscarito se junta a Grande Otelo, em um já célebre momento de apropriação de uma obra clássica para os fins cômicos da chanchada. A apropriação e adaptação nos tempos da Atlântida - em especial a partir da década de 1950 - se formalizou, principalmente, a partir do cinema norteamericano, parodiando superproduções hollywoodianas, em filmes como Nem Sansão, nem Dalila (dir. Carlos Manga, 1954) e Matar ou correr (dir. Carlos Manga, 1954): nessas obras, além da crítica velada ao governo de Getúlio Vargas, o domínio econômico da condição colonial brasileira manifestava-se também em domínio cultural, em que a paródia servia como escárnio ante a sua própria incapacidade de copiar (VIEIRA, 1983, p.22).

A cena do balcão construída no filme de Macedo tem a estrutura de um esquete, como os números musicais que se tornaram a marca da chanchada carioca: de fato, a cena não tem uma ligação direta com a trama do filme; ela se desenvolve de maneira autônoma, e boa parte de sua força expressiva, inclusive, provém dessa autonomia. Oscarito, no papel de Romeu, com seus trejeitos e feições, e Grande Otelo, travestido de uma Julieta loira, compõem uma atuação nitidamente exagerada, com os braços abertos de Romeu e o peito contrito de Julieta. 0 texto que falam é cheio de 
trocadilhos e sutilezas, os quais, como aponta Thaïs Flores Diniz (1999, p. 379), são "alusões a fatos culturais da época, jogos de palavras, gírias e incongruências - que fazem com que o sentido seja alterado e adquira o tom cômico presente na re-escrita de Watson Macedo, que passa a conter um duplo sentido, origem do humor e da ironia".

0 tipo de atuação "teatral" conduzido por Oscarito e Grande Otelo é assegurado por uma dupla motivação: no filme, os atores estão em um palco, representando a cena shakespeariana, no ensaio de um espetáculo que Ricardo (Anselmo Duarte) e Marina (Eliana) pretendem montar no Copacabana Palace; além disso, o efeito cômico é também garantido pelo choque entre uma atuação exagerada (típica do vaudeville e do teatro de revista), que é marcadamente dos personagens cômicos, e uma atuação mais recatada, naturalista, com a qual trabalham os personagens de Anselmo Duarte e Eliana. A mise-en-scéne da sequência também evidencia esse aspecto teatral ao mostrar Romeu e Julieta num palco, e Ricardo e Marina os assistindo: aqui, o olhar da câmera que capta a encenação de Oscarito e Grande Otelo se assemelha, por contingência, ao da plateia de teatro. Tal procedimento - que tanto destaca 0scarito e Grande Otelo por sua performance corporal, quanto cria através da mise-en-scène uma encenação dentro da encenação - acrescenta ao filme a dimensão de auto-reflexividade tão comum ao teatro shakespeariano.
Dessa maneira, a presença de Shakespeare em Carnaval no fogo segue princípio semelhante, uma vez que, além de ser considerado o mais alto grau de criação estética da literatura ocidental - não só pela qualidade literária do texto, mas pela inegável força da língua inglesa no domínio colonial - a obra shakespeariana, mesmo a cômica, representa um signo socialmente marcado de 'alta cultura'. Assim, encenar Oscarito como Romeu e Grande Otelo como Julieta, com seus gestos e expressões cômicas, re-significa o texto shakespeariano não só para a linguagem cinematográfica, mas, principalmente, para o contexto cultural específico das chanchadas da Atlântida. Como informa Hilda Machado:

A escolha do diretor Watson Macedo e seu coroteirista, Alinor de Azevedo, um dos melhores escritores de chanchadas, mostra 0 trabalho cuidadoso dos roteiristas, desmonta o emprego totalizante do conceito do mal-feito que ainda informa muita leitura da chanchada e reforça a tese de uma penetração da tragédia lírica de Shakespeare no final da década de 1940 em camadas cariocas para além da esfera culta e não habitualmente a ela relacionadas (MACHAD0, 2007, p. 61).

Outra chanchada que parodia Romeu e Julieta é Um candango na Belacap (dir. Roberto Farias, 1961), também com Grande Otelo no elenco, mas agora formando dupla com Ankito. Segundo Hilda Machado, a cena no filme de Roberto Farias é uma referência direta a Carnaval no fogo. Em Um candango na Belacap, a cena ocorre com Grande Otelo e Vera Regina, esta, caracterizada 
de Julieta. Hilda Machado assim analisa a relação entre os dois filmes: "A citação da cena do balcão em Carnaval no fogo é uma representação da própria história do artista Grande Otelo, e essa auto-reflexividade é uma tradição da paródia e da comédia. A nova chanchada citava a antiga; a sequência musical de Um candango na Belacap fez a paródia de uma sequência que era ela mesma uma paródia" (MACHAD0, 2007, p. 63). Nesse sentido, são filmes que estabelecem uma relação intertextual muito forte entre si, dialogando não apenas no universo da tradição, como no da própria relação do cinema brasileiro com Shakespeare.

As personagens de Grande Otelo e Vera Regina, em Um candango na Belacap, não remetem ao Romeu e Julieta de Shakespeare, mas à recepção de Shakespeare no Brasil dos anos 1950. Doze anos depois de Carnaval no fogo, Um candango na Belacap é um ícone da prolongada tensão estabelecida pela cultura popular carioca com a cultura erudita e a cultura americana (MACHADO, 1997, p. 63).

Assim, como veremos logo adiante, em relação aos filmes diretamente adaptados de Romeu e Julieta, a principal característica que se evidencia é 0 embate entre as formas culturais a que o teatro de Shakespeare está associado (em especial, o elitismo da cultura do letramento e a anglofonia) e os gêneros, contextos e especificidades da cultura brasileira que, como os filmes demonstram, se posiciona em permanente tensão de significado com a matriz shakespeariana.

\section{Romeu e Julieta no Brasil}

A relação que os filmes brasileiros adaptados de Romeu e Julieta estabelecem com o texto-fonte é sempre mediada por outros gêneros, retóricas ou mesmo produtos culturais (como histórias em quadrinhos ou times de futebol), diretamente ligados com o imaginário e a cultura nacionais. Na composição da história, percebe-se apenas a manutenção de algumas cenas paradigmáticas da peça (como a do balcão, a da festa e a da morte do casal) e a estrutura principal da trama, ainda que re-significada em outros contextos: a briga entre os pais dos jovens apaixonados, que interfere no relacionamento, pode ser tornar conflito de classe, de grupos rivais do tráfico ou de torcidas de futebol. Além disso, todos os filmes se empenham em inserir a trama da peça num contexto e numa retórica brasileiros, seja pelo espaço de encenação em que o filme é locado, seja por signos (músicas, sotaques, gírias e outras práticas culturais) que informam e localizam 0 filme no Brasil.

\section{A primeira obra a adaptar Romeu e} Julieta data de 1979 e é, na verdade, um produto híbrido: chama-se Mônica e Cebolinha no mundo de Romeu e Julieta, e foi um especial feito para a TV Bandeirantes a partir da peça teatral homônima e, em seguida, lançado no cinema e depois em VHS. Dirigido por José Amâncio, sob supervisão de Maurício de Souza, o filme tem locações em Ouro Preto-MG, com atores reais usando máscaras dos famosos personagens das 
histórias em quadrinhos da Turma da Mônica. 0 filme é, na verdade, uma adaptação da versão dos quadrinhos para o teatro (considerada o maior sucesso da Turma da Mônica nos palcos), escrita por Yara Maura e por ela mesma roteirizada para 0 filme. Aqui, podemos perceber 0 grau de circularidade em que a obra shakespeariana foi inserida: das histórias em quadrinhos, para o teatro, depois, para a televisão e, por último, para 0 cinema e o homevideo. A adaptação, nesse sentido, segue o caminho que em muito define as escolhas a partir das quais os produtos são recriados em meios diferentes: 0 sucesso de uma obra impulsiona sua adaptação, que impulsiona outra e outra e, assim, sucessivamente.

Com tom de história infanto-juvenil, a trama de Mônica e Cebolinha no mundo de Romeu e Julieta se desenvolve a partir das músicas que já haviam feito sucesso na peça teatro e que saíram anteriormente em LP. Aqui, Romeu Montéquio Cebolinha e Julieta Monicapuleto apaixonam-se, e a briga entre as famílias atravanca a relação. A construção dos personagens é muito particular: Romeu é uma espécie de malandro, que quer arrumar outra namorada depois que terminou com Rosalina. Ele conhece Julieta na festa dos Capuletos (para a qual fora sem ser convidado), e, vai, após um número musical em que Julieta e Amagali cantam um samba-canção, para a varanda de seu castelo, dizendo: "Lá vou eu para a famosa cena da sacada". Esse tipo de referência ao tema shakespeariano, em que os personagens dentro da trama têm consciência de participar de uma "história que se repete", é uma das principais características dos filmes shakespearianos no Brasil.

Ao contrário de Romeu, Julieta é uma personagem forte, ao ponto de ser ríspida e bruta - tal qual a Mônica das histórias em quadrinhos. Na cena do balcão, ela exige que Romeu suba para beijá-la, mas este, todo atrapalhado, não consegue. Depois de ouvir o pai de Julieta perguntando que barulho era aquele, o casal se despede e Julieta marca um encontro para o dia seguinte, junto à Igreja de Frei Lourenço Cascão para o casamento. "Casamento? Mas quem falou em casamento?", pergunta Romeu. "Nós", responde Julieta. No dia seguinte, na espera do Frei Cascão, Romeu pensa alto: "essas galotas são todas iguais, nem bem começa o namolo, já vêm falando em casamento".

Outra situação importante ocorre quando Frei Cascão e Julieta estão pensando em uma solução para o caso de Romeu, que, no campeonato de bolinhas de gude, interferiu na briga entre Zé Lelé Mercúcio e Chico Bento Tebaldo, derrotando esse último. 0 príncipe Xaveco de Verona, que havia proibido brigas, expulsou Romeu da cidade. Com isso, Frei Cascão pensa numa saída para Julieta e Romeu e sugere consultarem um livro: o volume grande, com letras em caligrafia trabalhada, mostra: Romeu e Julieta, de Shakespeare. Mais uma vez, o recurso à auto-referência alicerça o filme. Logo 
em seguida, Julieta sugere: "Procura um final feliz aí pra gente...".

0 fim do filme mostra a sequência do envenenamento do casal, em que Romeu e Julieta se deitam e Frei Cascão começa a rezar pelos amantes mortos. Julieta, porém, se levanta e reclama que não, assim não pode, 0 final foi muito triste. E Romeu, também erguido, corrige Julieta: "no Shakespeare é assim, tudo muito lomântico, tudo muito bonito, mas muito tliste também.

Lomeu e Julieta se saclificalam muito, mas foi assim que as duas famílias fizelam as pazes...". Ao que Julieta, no tom orgulhoso e duro que lhe caracteriza, responde: "Ah, é? Mas eu não topo. Shakespeare que me desculpe, mas eu vou dar um outro jeito no final dessa história". Ela então vai ao encontro do príncipe Xaveco de Verona, lhe dá umas coelhadas na cabeça e Romeu é perdoado.

No fim, ainda com receio de se casar com Julieta, Romeu tenta despistá-la. Mas Frei Cascão, dizendo que aquela história deu muito trabalho para não ter um final feliz, empurra Romeu para Julieta e todos, de repente, estão numa boate, com a luz em néon típica de fins dos anos 1970, cantando a música final do filme.

É importante enfatizar que a adaptação do filme Mônica e Cebolinha no mundo de Romeu e Julieta, embora seja mediada pelos quadrinhos, depois pela peça de teatro, pelo especial de televisão e, por último, pelo cinema, mantém muito presente a história que lhe serviu de fonte, inserindo na imagem, inclusive, a materialidade do livro Romeu e Julieta. Os personagens têm consciência da encenação em que se encontram - sabem de Shakespeare e do texto-fonte, mas, apesar da deferência, investem para transformálo, para melhorá-lo a partir das convenções genéricas do filme (nesse caso, a comédia musical infanto-juvenil). A fala de Julieta, que interfere incisivamente no texto shakespeariano, é uma aula de adaptação: embora respeite a história escrita por Shakespeare, decide mudá-la para que se ajuste melhor aos fins próprios de seu gênero fílmico.

Mais de vinte anos depois, em 2003, é lançado o filme Didi, o cupido trapalhão (dir. Paulo Aragão e Alexandre Boury), que retoma e atualiza a trama de Romeu e Julieta. Mais uma vez, Renato Aragão utiliza o tema shakespeariano para construir uma história: aqui, um anjo, após muito bagunçar 0 céu, é mandado para a Terra como cupido, com a incumbência de unir ao menos um casal para voltar ao paraíso. Nas suas buscas, ele se depara com o entregador de pizza Romeu (Daniel), pobre rapaz que sonha em ser cantor. Didi lhe promete ajudar a ser cantor e a arranjar uma namorada, ao que Romeu não acredita.

Do outro lado da rua, vê uma jovem e rica loira (Jaqueline Petkovic), e decide que ela será a namorada de Romeu. Didi, de forma um tanto inverossímil, começa a trabalhar de mordomo na mansão de Dr. Poleto (Mauro Mendonça), pai da moça, que se chama Julieta e está prometida para casar com o empresário Páris (Aramis Trindade). 
Enquanto arruma uma série de confusões para juntar o casal, dois anjos acompanham do céu as peripécias de Didi. Ao ouvir que os nomes do rapaz e da moça são Romeu e Julieta, eles se assustam e comentam que Didi escolheu 0 casal mais difícil de unir. Mais uma vez, estamos diante de uma consciência da fonte literária que alicerça a história. Romeu e Julieta da história atualizada no filme não estão afastados do texto shakespeariano: pelo contrário, os personagens denotam conhecer a história anterior.

Isso fica evidenciado no momento em que Didi, percebendo que Julieta está prometida por seu pai para casar com Páris, puxa Romeu para um lado e diz: "Não, isso não vai dar certo. Você não conhece a história? Shakespeare...". A consciência do tema shakespeariano perpassa a história, deixando nítida a tensão entre a manutenção da estrutura original (especialmente 0 final trágico que não combina com as convenções da comédia) e a atualização para a realidade e a cultura brasileira. 0 conflito entre as famílias é transformado em conflito social (Julieta é de família rica e Romeu, pobre, nem família tem), permitindo a expressão do ideário romântico, perpetuado pelas matrizes melodramáticas, de que 0 amor vence quaisquer barreiras (ideário que está distante do texto shakespeariano - como nos diz Harold Bloom (2001, p. 132), "é o fim do amor ou o fim da vida").

No caso de Didi, o cupido trapalhão, temos também a cena do balcão, a festa dos Capuletos e a morte por envenenamento. Nesta última, Didi combina com Julieta para fingir a morte para o Sr. Poleto, a fim de que este valorize a vida e 0 amor da filha. Durante o filme, 0 quarto de Didi (lembremos que ele é um anjo) é mostrado como uma espécie de laboratório, em que ele coleta plantas e delas produz medicamentos. Em cena, no meio do filme, a empregada Suzy (Helen Ganzarolli) pergunta a Didi o que é um frasco vermelho com a tradicional marca de caveira no centro. Didi explica que é um veneno que pode matar alguém em poucos minutos. Quando Romeu, no fim do filme, vê Julieta presumidamente morta, pega então o frasco de veneno e 0 toma. Julieta em seguida acorda e, notando que Romeu não sabia do estratagema e que tomara 0 veneno, bebe 0 restante do frasco e também cai desfalecida. 0 Dr. Poleto, junto com o restante da família e amigos, chora sobre o corpo da filha e diz: "se eu pudesse voltar atrás, teria permitido que eles se casassem". Romeu se levanta, diz: "combinado" e sai correndo para tirar um pequeno rato que entrara em suas calças. Sem entender direito, Suzy pergunta a Didi se aquilo era mesmo veneno, ao que ele diz que sim e que também não entende o que se passa. Após isso, aparecem os dois anjos no céu e um deles, com o frasco de veneno na mão, fala para o outro: "eu troquei, mas não comenta com ninguém".

Novamente, a necessidade de construir um final feliz para a história é assegurada por um personagem dentro da trama (ainda que com 
atribuições de Deus ex machina). Aqui, o anjo tem as funções simbólicas de um adaptador: consciente da história que serviu de fonte e da necessidade do gênero fílmico em ter um final feliz, ele interfere no desenrolar da trama, deixando claro que, como personagem, ele está também adaptando Shakespeare. Este, com isso, não sai do horizonte de significado do filme, estando presente de forma direta (seu nome é até mesmo pronunciado por um dos personagens), ainda que as convenções genéricas do filme imponham sua transformação.

No ano seguinte a Didi, o cupido trapalhão, é lançado o filme $O$ casamento de Romeu e Julieta, dirigido por Bruno Barreto. Refratando a tragédia shakespeariana através de outra obra - de fato, o filme é declaradamente baseado do conto

Palmeiras, um caso de amor, de Mário Prata -, o filme de Barreto se apropria da tradicional rivalidade entre Palmeiras e Corinthians, clubes de futebol da cidade de São Paulo, para encenar o conflito das famílias Montéquio e Capuleto: Alfredo Baragatti (Luis Gustavo), um palmeirense tradicional (advogado, descendente de italianos e membro do Conselho Deliberativo do clube), tem uma filha, Julieta (Luana Piovani), criada para ser mais uma apaixonada pelo time. Ela é jogadora do time feminino do Palmeiras, e tudo ao seu redor gira em torno do clube: sua rotina, suas roupas, até a colcha em que dorme fazem referência ao brasão do time. 0 caso é que Julieta, então, se apaixona por Romeu (Marco Ricca), corintiano fanático. Ao descobrir a paixão futebolística de Julieta, Romeu finge ser palmeirense, criando uma série de quiproquós com o futuro sogro. 0 impasse que é criado estabelece a tensão dramática e as situações cômicas que guiarão o desenrolar da história.

0 modo como os dois se conhecem é construído a partir de um jogo de olhares que encena 0 envolvimento do casal, enfatizando a visão como estopim da paixão: Julieta está na arquibancada, assistindo mais um Palmeiras e Corinthians com seu pai. Após o gol palmeirense, e a devida comemoração da torcida, ela observa os corintianos ao lado, cabisbaixos. Um torcedor subitamente se ergue e começa a vibrar, estimulando os demais, que se levantam e entoam as tradicionais canções de estímulo. Julieta, então, pega uns binóculos e o observa. A câmera assume o olhar de Julieta, marcando os contornos dos binóculos, e Romeu se destaca da multidão. Depois do jogo, na saída do estádio, as torcidas estão separadas por hastes de ferro e policiais, enquanto os torcedores rivais (entre eles, Romeu, de um lado, e Julieta, do outro) trocam pilhérias e ofensas.

Após esse primeiro contato visual, enfatizado pela encenação do olhar de Julieta, é também pela visão que ela chega até Romeu. Após a diretoria do Palmeiras cancelar o time de futebol feminino (do qual Julieta é a mais entusiasta), ela briga com o pai, que não interferiu em favor dela junto à diretoria. Num ímpeto, ela pega a faixa de "Rainha do Palmeiras" e joga na lareira. 
Seu pai, tentando resgatar a faixa, puxa-a do fogo, mas fagulhas escapam e atingem o olho de Julieta. Levada para o hospital, ela vai à sala de oftalmologia, põe o rosto no aparelho de exames e espera o médico, que não tarda em chegar: Romeu, o objeto de seu olhar pelos binóculos, agora foca direto em seu olho machucado. Ao som de uma música romântica, que climatiza a situação, Romeu então afasta 0 aparelho e encara Julieta longa e demoradamente, e ela retribui com a expressão langorosa.

A encenação desse jogo de olhares, modulado, primeiramente, pela atenção de Julieta com os binóculos, e, depois, pela resposta de Romeu com 0 aparelho oftalmológico, representa 0 famoso "amor à primeira vista" que tanto remete à história de Romeu e Julieta. De fato, essas cenas são construídas de forma a atualizar 0 tema shakespeariano no contexto do filme, caracterizando os personagens e utilizando, por fim, uma estratégia de linguagem muito própria do cinema clássico-narrativo: posicionar os personagens na mise-en-scène como agentes e objetos de olhar, junto aos quais a câmera se associa, seja incorporando fisicamente o olhar de um personagem (na estrutura clássica do plano ponto de vista), seja mostrando uma troca de olhares dentro do plano.

No filme, podemos notar duas referências mais diretas a Shakespeare e sua peça: quando saem pela primeira vez, Julieta explica a Romeu o motivo de seu nome: "não foi por causa de
Shakespeare...", diz ela. De fato, Julieta fora batizada em homenagem a dois ídolos dos Palmeiras: "Juli", de Julinho (famoso pontadireita de fim dos anos 1950) e "Eta" de Echevarrieta (atacante do clube nos anos 1940). Dessa forma, a ideia do nome Julieta serve para um duplo propósito: primeiro, demonstra o fanatismo do senhor Baragatti em relação ao Palmeiras (fato que impulsionará o conflito dramático); além disso, estabelece uma relação com a matriz shakespeariana - embora Julieta afirme que seu nome não tem relação com Shakespeare, o fato de mencioná-lo impele 0 espectador, para além da óbvia informação já contida no título, a relacionar o filme com o tema shakespeariano.

Outra referência ocorre próximo ao fim do filme. Depois de revelada a mentira, e de Julieta ter fugido para o apartamento de Romeu, Baragatti vai em busca da filha, causando uma série de confusões no local. Após o clímax do filme, em que Julieta pede ao pai que a entenda e a deixe ser feliz, Romeu fica na quadra do prédio, olhando para a lua e falando com São Jorge (santo padroeiro do Corinthians). Com a lua bem desenhada no céu, a câmera lentamente caminha para a esquerda, mostrando as janelas do prédio. Numa delas, em cuja armação está pendurada uma bandeira corintiana, Julieta olha para baixo, em direção a Romeu. Embora muito curto, e sem nenhum diálogo entre os personagens, esse momento é uma referência direta à cena do balcão. 
Assim, desvinculada de seu destino trágico, a história de Romeu e Julieta se firma como uma comédia romântica. Nesse sentido, vincular 0 filme a Romeu e Julieta já no título - mesmo sendo, na verdade, adaptação de outra obra trata-se de uma estratégia cultural que busca um signo de referência com a qual a grande maioria interage. Ir ao cinema ver um filme intitulado O casamento de Romeu e Julieta é acompanhar a história de amor mais popular da cultura ocidental; neste caso, com uma diferença: o desfecho trágico é imediatamente substituído pelo happy end denunciado no "casamento" do título. Assim, a adaptação do tema shakespeariano é mais uma vez impulsionada pelas convenções do gênero, permitindo as transformações do enredo, dos personagens e do próprio teor da história.

Como temos demonstrado ao longo deste artigo, as transformações que os filmes fazem na matriz shakespeariana são motivadas pelas convenções genéricas junto às quais os filmes se constroem. Nessa linha, seguem dois filmes recentes: Maré, nossa história de amor (dir. Lúcia Murat, 2007) e Era uma vez... (dir. Breno Silveira, 2008). A história de Romeu e Julieta é apropriada, em ambos, para encenar os conflitos sociais de favelas do Rio de Janeiro. Maré é um musical que remete a Amor sublime amor (West side story, dir. Robert Wise e Jerome Robbins, 1961), também uma adaptação de Romeu e Julieta: encena a história de amor proibido entre membros de duas facções rivais da favela da Maré, utilizando um repertório musical que enfatiza temas do rap, do samba e do street dance, bem como canções da música popular brasileira. Esse painel de referência musical caracteriza indicialmente a trama: 0 casal protagonista, Jonatha (Vinícius D'Black) e Analídia (Cristina Lago), integra um grupo local de dança - organizado pela professora Fernanda (Marisa Orth), que é do asfalto - e, além disso, cada qual pertence a um lado da divisão do morro: Jonatha é irmão de Dudu, chefe da facção azul, e Analídia é filha do chefe da facção vermelha, preso na cadeia, e está sob a responsabilidade de Bê (Jefchander Lucas).

Essa divisão vai, ao longo do filme, tornando-se mais acirrada: Jonatha e Analídia, para ficarem juntos, têm que sair do morro. Fernanda tenta conseguir duas bolsas de estudo para eles irem dançar na Europa, mas as tensões ficam mais intensas quando Dudu mata Anjo (Anjo Lopes), ex-traficante do lado vermelho, que trocara 0 tráfico pela dança, e que funciona como Tebaldo na matriz shakespeariana: sua morte impulsiona a perseguição a Jonatha, que tem que fugir imediatamente. Fernanda propõe então uma saída: fingir a morte de Jonatha e tirá-lo do morro escondido em um caixão - invertendo os papéis da peça shakespeariana, em que é Julieta que, primeiramente, finge o suicídio. A ideia, como sempre, resulta inútil: Dudu, num ímpeto de fúria diante do irmão supostamente morto, dispara vários tiros no caixão, matando Jonatha de fato. No outro lado do morro, a notícia 
da suposta morte de Jonatha chega a Analídia, que corre alucinada no meio de uma troca de tiros e é fatalmente atingida. Assim, a morte do casal encena o processo de atualização da trama shakespeariana no contexto em que 0 filme se insere: os jovens são mortos por armas de fogo, e 0 fim trágico deles nem de longe promete a pacificação do lugar ou a união das facções rivais. De fato, a estrutura social é muito mais forte e opressora, não permitindo a ilusão de uma comunhão partilhada.

É importante também notar que a inserção da trama de Shakespeare no contexto das favelas cariocas permite atualizar cenas-chave da peça sem se afastar do ambiente da encenação. A festa em que o casal se apaixona, por exemplo, se transforma em um baile funk, com a música e a dança articulando o desenvolvimento dramático da cena, que termina com uma briga (coreografada e musical) entre as facções rivais. Nessa festa, aparecem três rappers que funcionam como um coro, que, através de seus versos, comentam algumas cenas durante 0 filme. Outra cena fundamental é a noite de amor do casal, que ocorre na escola de dança, em meio a fantasias, alegorias e imagens carnavalescas. A cena do balcão também ocorre, ainda que de modo rápido e pouco enfático: Analídia está na janela de seu barraco e Jonatha, que viera sorrateiramente até 0 local, acena de fora e ela desce. Ambos então saem pelas ruelas, de mãos dadas, ao que se segue mais uma intervenção dos três rappers.
Apesar disso, a principal cena que sustenta a relação do filme com a matriz shakespeariana é mediada por outro tipo de adaptação: os alunos da escola de dança assistem a um vídeo do balé Romeu e Julieta (1935-1936), de Sergei Prokofiev. 0 recurso à auto-referência é mais uma vez utilizado para relacionar a matriz shakespeariana (aqui, em diálogo com outra forma de adaptação), fazendo, inclusive, os personagens refletirem sobre 0 próprio ato de adaptar. Um dos alunos, ao fim da exibição, comenta: "história bonita, legal, só que está faltando algumas coisas: um DJ, roupas largas...". A professora Fernanda, então, pergunta: "Você acha que dava para ter uma história de Romeu e Julieta com hip-hop?", ao que outro aluno responde: "Cada dança tem o seu vocabulário. Cabe a quem produz, a quem faz, tirar o melhor do que a gente tem em cada modalidade, pra poder mostrar uma história com um certo conteúdo". Essa frase, dita com a naturalidade de um gíria, câmera na mão se aproximando do rosto do garoto, é uma ilustração direta do que significa adaptar para meios diferentes (cada qual com seu "vocabulário") e para culturas diferentes (nesse caso, o hip-hop). Com isso, Maré, nossa história de amor constrói um momento de reflexão sobre o processo de adaptação, como a Julieta em Mônica e Cebolinha no mundo de Romeu e Julieta, e como o anjo que troca os venenos em Didi, o cupido trapalhão: as histórias devem ser re-escritas, no esforço de melhor inseri-las no contexto em que 0 filme se situa e nos gêneros com os quais dialoga. 
Finalmente, temos o mais recente Romeu $e$

Julieta brasileiro: Era uma vez..., de Breno Silveira. 0 embate migra agora para um conflito entre classes sociais, transformando as famílias rivais em morro e asfalto, em que Dé (Thiago Martins), morador do morro do Cantagalo, e Nina (Vitória Frate), que mora num apartamento na tradicional Avenida Vieira Souto, em Ipanema, formam o casal apaixonado. A história começa com a infância de Dé, que vê o seu irmão Beto (Fernando Brito) ser assassinado por um traficante e seu outro irmão, Carlão (Rocco Pitanga), ser exilado da favela. Em uma confusão na praia, em que o garoto Dé escondera uma arma na barraca de cachorro-quente de Carlão na praia, este é preso e passa vários anos na cadeia.

Com o tempo, Dé passa a trabalhar em um quiosque na praia de Ipanema, de onde observa a janela do apartamento de Nina (em uma referência direta ao balcão Romeu e Julieta). Sua atenção se volta diariamente a ela, acompanhando de longe, como um voyeur, o fim do namoro dela diante do portão, as saídas dela para a praia e a movimentação na janela do apartamento. Para conhecê-la, Dé finge ser surfista, entra de penetra numa rave na praia (que, junto a um baile funk no morro, fazem uma dupla referência à festa dos Capuletos na peça de Shakespeare), até que, finalmente, consegue beijá-la. Nina, mesmo depois de descobrir a origem de Dé, não se nega a continuar com ele. A incompatibilidade do relacionamento, no entanto, é tornada patente pelo pai dela (Paulo César Grande), viúvo e que tem Nina como filha única.

Quando Carlão, após deixar a cadeia, toma 0 morro e passa a implementar várias melhorias para a população (entre elas, um chafariz para as crianças se molharem) e a vida no morro parece tranquilizar-se, Dé e Nina resolvem ir para 0 nordeste, começar uma vida nova, sem os preconceitos por causa da origem dele. No entanto, devido às dívidas acumuladas nessas melhorias, Carlão resolve sequestrar Nina e exigir o resgate para o pai dela. Dé descobre o sequestro, invade 0 cativeiro e resgata Nina - porém, a partir de agora, ele é considerado o responsável pelo sequestro. 0 fim trágico de Romeu e Julieta é aqui atualizado no momento em que a fuga dos jovens (que escapam da perseguição da polícia e dos repórteres) acaba na barraca de Dé, em frente ao prédio de Nina. Lá dentro, cercados pelos policiais, pela imprensa e por familiares e amigos dos dois, Dé tem a consciência de que, mesmo se sair dali com vida, eles não conseguirão ficar juntos. Assim, eles saem da barraca, ele com a arma apontada para ela, mas dizendo que se entregará. Até que um tiro acerta Dé, que cai morto no chão. Nina, completamente aturdida, pega a arma e atira em direção aos policiais, que revidam e também ela morre. A impossibilidade da união é aqui sacramentada pela interferência direta do Estado (através da força policial) e da própria 
mídia (pela espetacularização do sequestro), que endossam a separação entre o morro e a favela. A morte do casal, nesse caso, não aventa nenhuma chance de conciliação nesse conflito - pois, da mesma forma que em Maré, nossa história de amor, o fosso social não pode, nem será aterrado com um beijo ou com um aperto de mão.

Intensamente carregado de um tom de fábula moral (já evidenciado no título, que remete aos contos de fada), Era uma vez... adapta a história de Romeu e Julieta em diálogo com outra obra: o livro-reportagem Cidade Partida, de Zuenir Ventura. 0 livro, que aparece fisicamente nas mãos dos personagens, é um relato do autor depois de passar nove meses na favela de Vigário Geral (onde ocorreu a famosa chacina de 1993), mostrando o cotidiano e as condições de vida da população do local. Assim, o conflito entre as famílias na peça shakespeariana é usado como referência à noção de "cidade partida": ou seja, é através da união da trama da peça com a divisão social que separa morro e asfalto que o filme atualiza Shakespeare - dando-lhe outra forma, noutro gênero e com sentidos outros.

\section{Considerações finais}

Em um momento da cena do balcão em Carnaval no fogo, com Oscarito como Romeu e Grande Otelo como Julieta, acontece 0 seguinte diálogo:

Julieta: Ouço passos lá dentro. Vai, Romeu, ele quer te matar! Romeu: Ele quem? Julieta: 0 meu pai, o senhor de Capuleto. Se ele te vir aqui...

Romeu: Vai ser um espeto!

Essas quatro linhas sintetizam 0 argumento exposto neste artigo acerca dos filmes brasileiros adaptados de Romeu e Julieta. Ao se apropriar da matriz shakespeariana para criar um esquete cômico, Watson Macedo e Alinor de Azevedo põem em choque tradições, gêneros e linguagens que aumentam exponencialmente as camadas de significado da cena como um todo. Ao invés de simplesmente buscar em Shakespeare uma ou mais sequências, transpondo-as o mais aproximado possível do texto-fonte, em Carnaval no fogo é precisamente a tensão genérica que sintetiza o embate entre comédia carioca e tragédia elisabetana, dando à cena a enorme carga expressiva que lhe é característica.

De modo semelhante, os filmes que adaptam Romeu e Julieta no Brasil não se limitam a buscar no texto shakespeariano alguns elementos para transpô-los de maneira fidedigna, ou mesmo apenas a estrutura dessa trama tão famosa. Seja ao propor uma reflexão sobre o próprio processo adaptativo (Mônica e Cebolinha..., Maré..., ou Didi, o cupido trapalhão), seja ao inserir a história em um contexto determinado, que modela a matriz shakespeariana a partir das especificidades genéricas (O casamento de Romeu e Julieta ou Era uma vez...), os filmes demonstram que a presença de Shakespeare no cinema brasileiro, apesar de toda carga simbólica que pesa na obra do Bardo inglês, 
ocorre numa constante inter-relação entre texto e contexto, em que os significados são produzidos precisamente através do choque entre ambos.

Nesse sentido, é fundamental perceber que a estratégia de Shakespeare, ao adaptar para 0 teatro a história de Romeu e Julieta (famoso conto italiano, traduzido na Inglaterra por Arthur Brooke), representou uma das mais importantes misturas de gêneros da história da literatura. 0 tema do amor, nos palcos, sempre foi típico do universo da comédia (pensemos em Plauto, Menandro e nas próprias comédias shakespearianas). Assim, ao levar 0 amor trágico para o teatro, Shakespeare nos mostra uma das contribuições mais valiosas da sua literatura: as histórias podem e devem ser reescritas, recriadas, re-significadas. 0 próprio Shakespeare, inclusive, é universal não porque ele pode ser lido em qualquer contexto, mas porque os contextos podem lê-lo e reinventá-lo, dando-lhe mais sentido - e mais vida.

\section{Referências}

BLO0M, Harold. Shakespeare: a invenção do humano. Rio de Janeiro: Objetiva, 2001.

DINIZ, Thaïs Flores. Shakespeare em paródia: Romeu e Julieta no Brasil dos anos 50. In: MENDES, Elianne; OLIVEIRA, Paulo; BENNIBLER, Veronika (orgs.). Revisitações: 30 anos. Belo Horizonte: FALE/UFMG, 1999. p. 375-384. MACHADO, Hilda. Entre a chanchada e a Vera Cruz: Oscarito, Grande Otelo e a negação do amor. In: Alceu: Revista de comunicação, cultura e política, Rio de Janeiro, v. 8, n. 15, p. 60-67, jul./dez. 2007.

MIRANDA, Luiz Felipe; RAMOS, Fernão.

Enciclopédia do cinema brasileiro. São Paulo: SENAC, 2000.

NOBRE, F. Silva. Shakespeare e o cinema. Rio de Janeiro: Pongetti, 1964.

VIEIRA, João Luiz. Este é meu, é seu, é nosso: introdução à paródia no cinema brasileiro. Filme Cultura, Rio de Janeiro, v. XVI, n. 41/42, p. 22-29, maio 1983. 


\section{Romeo and Juliet on} Brazilian cinema: adaptation, appropriation and intertexts

\section{Abstract}

This paper intends to analyze the various ways of appropriation of the play Romeo and Juliet (1595-1596), by William Shakespeare, into Brazilian cinema. These movies, either with the appropriation of one or more scenes, or with the construction of the narrative from the plot of the play, put the Shakespearean text in a permanent sense tension between the context and the genres in which they are created. In this sense, we seek to investigate the way these movies re-create the story of Romeo and Juliet, emphasizing how each one tries to develop new ways to express the Shakespearean theme, by the dialogue with popular comedy, musical and urban drama in Brazil.

\section{Keywords}

Shakespeare in cinema. Cinematographic adaptation. Brazilian cinema. Incommunication.

\section{Romeo y Julieta en el cine brasileño: adaptaciones, apropiaciones e intertextos}

\section{Resumen}

Este artículo investiga las diversas formas de apropiación de Romeo y Julieta (1595-1596), de William Shakespeare, en el cine brasileño. Las películas, sea al apropiar uno o más escenas, sea al escribir la historia desde el argumento de la obra, ponen el texto de Shakespeare en constante tensión de significado con los contextos y géneros en que se encuentran las películas. En ese sentido, tenemos la intención de investigar la manera cómo estas películas re-inventan la historia de Romeo y Julieta, haciendo hincapié en cómo cada uno se esfuerza para crear nuevas formas de expresión del tema de Shakespeare, desde el diálogo con la comedia popular, el musical y el drama urbano en Brasil.

\section{Palabras clave}

Shakespeare en el cine. Adaptación cinematográfica. Cine brasileño. 


\section{Expediente}

A revista E-Compós é a publicação científica em formato eletrônico da Associação Nacional dos Programas de Pós-Graduação em Comunicação (Compós). Lançada em 2004, tem como principal finalidade difundir a produção acadêmica de pesquisadores da área de Comunicação, inseridos em instituições do Brasil e do exterior.
E-COMPÓS I www.e-compos.org.br I E-ISSN 1808-2599

Revista da Associação Nacional dos Programas de Pós-Graduação em Comunicação. Brasília, v.12, n.3, set./dez. 2009.

A identificação das edições, a partir de 2008 passa a ser volume anual com três números.

\section{CONSELHO EDITORIAL}

Afonso Albuquerque

Universidade Federal Fluminense, Brasil

Alberto Carlos Augusto Klein

Universidade Estadual de Londrina, Brasi

Alex Fernando Teixeira Primo

Universidade Federal do Rio Grande do Sul, Brasil

Alfredo Vizeu

Universidade Federal de Pernambuco, Brasi

Ana Carolina Damboriarena Escosteguy

Pontifícia Universidade Católica do Rio Grande do Sul, Brasil

Ana Silvia Lopes Davi Médola

Universidade Estadual Paulista, Brasil

André Luiz Martins Lemos

Universidade Federal da Bahia, Brasil

Ângela Freire Prysthon

Universidade Federal de Pernambuco, Brasil

Antônio Fausto Neto

Universidade do Vale do Rio dos Sinos, Brasil

Antonio Carlos Hohlfeldt

Pontifícia Universidade Católica do Rio Grande do Sul, Brasil

Arlindo Ribeiro Machado

Universidade de São Paulo, Brasil

César Geraldo Guimarães

Universidade Federal de Minas Gerais, Brasi

Cristiane Freitas Gutfreind

Pontifícia Universidade Católica do Rio Grande do Sul, Brasil

Denilson Lopes

Universidade Federal do Rio de Janeiro, Brasil

Eduardo Peñuela Cañizal

Universidade Paulista, Brasil

Erick Felinto de Oliveira

Universidade do Estado do Rio de Janeiro, Brasil

Francisco Menezes Martins

Universidade Tuiuti do Paraná, Brasil

Gelson Santana

Universidade Anhembi/Morumbi, Brasil

Goiamérico Felício

Universidade Federal de Goiás, Brasil

Hector Ospina

Universidad de Manizales, Colômbia

Herom Vargas

Universidade Municipal de São Caetano do Sul, Brasil

leda Tucherman

Universidade Federal do Rio de Janeiro, Brasil

Itania Maria Mota Gomes

Universidade Federal da Bahia, Brasil

Janice Caiafa

Universidade Federal do Rio de Janeiro, Brasil

Jeder Silveira Janotti Junior

Universidade Federal da Bahia, Brasil

\section{João Freire Filho}

Universidade Federal do Rio de Janeiro, Brasil

John DH Downing

University of Texas at Austin, Estados Unidos

José Luiz Aidar Prado

Pontifícia Universidade Católica de São Paulo, Brasil

José Luiz Warren Jardim Gomes Braga

Universidade do Vale do Rio dos Sinos, Brasi

Juremir Machado da Silva

Pontifícia Universidade Católica do Rio Grande do Sul, Brasil

Lorraine Leu

University of Bristol, Grã-Bretanha

Luiz Claudio Martino

Universidade de Brasília, Brasil

Maria Immacolata Vassallo de Lopes

Universidade de São Paulo, Brasil

Maria Lucia Santaella

Pontifícia Universidade Católica de São Paulo, Brasil

Mauro Pereira Porto

Tulane University, Estados Unidos

Muniz Sodre de Araujo Cabral

Universidade Federal do Rio de Janeiro, Brasil

Nilda Aparecida Jacks

Universidade Federal do Rio Grande do Sul, Brasil

Paulo Roberto Gibaldi Vaz

Universidade Federal do Rio de Janeiro, Brasil

Renato Cordeiro Gomes

Pontifícia Universidade Católica do Rio de Janeiro, Brasil

Ronaldo George Helal

Universidade do Estado do Rio de Janeiro, Brasil

Rosana de Lima Soares

Universidade de São Paulo, Brasil

Rossana Reguillo

Instituto Tecnológico y de Estudios Superiores do Occidente, México

Rousiley Celi Moreira Maia

Universidade Federal de Minas Gerais, Brasil

Samuel Paiva

Universidade Federal de São Carlos, Brasil

Sebastião Albano

Universidade Federal do Rio Grande do Norte, Brasil

Sebastião Carlos de Morais Squirra

Universidade Metodista de São Paulo, Brasil

Simone Maria Andrade Pereira de Sá

Universidade Federal Fluminense, Brasi

Suzete Venturelli

Universidade de Brasília, Brasil

Valério Cruz Brittos

Universidade do Vale do Rio dos Sinos, Brasil

Veneza Mayora Ronsini

Universidade Federal de Santa Maria, Brasil

Vera Regina Veiga França

Universidade Federal de Minas Gerais, Brasi

\section{COMISSÃO EDITORIAL}

Felipe da Costa Trotta I Universidade Federal de Pernambuco, Brasil Rose Melo Rocha I Escola Superior de Propaganda e Marketing, Brasil

\section{CONSULTORES AD HOC}

Arthur Autran Franco de Sá Neto I Universidade Federal de São Carlos

Carlos Eduardo Franciscato I Universidade Federal de Sergipe

Elisa Reinhardt Piedras I Universidade Federal do Rio Grande do Su

Elizabeth Bastos Duarte I Universidade Federal de Santa Maria

Marcia Benetti Machado I Universidade Federal do Rio Grande do Sul

Sandra Maria Lúcia Pereira Gonçalves I Universidade Federal do Rio Grande do Sul

Suzana Kilpp I Universidade do Vale do Rio dos Sinos

Tattiana Gonçalves Teixeira I Universidade Federal de Santa Catarina

Vander Casaqui I Escola Superior de Propaganda e Marketing

Vicente Gosciola I Universidade Anhembi Morumbi

Walter Teixeira Lima Junior I Fundação Cásper Líbero

REVISÃO DE TEXTO E TRADUÇÃO I Everton Cardoso

EDITORAÇ̃̃ ELETRÔNICA I Raquel Castedo
COMPóS I www.compos.org.br

Associação Nacional dos Programas de Pós-Graduação em Comunicação

Presidente

Itania Maria Mota Gomes

Universidade Federal da Bahia, Brasil

itania@ufba.br

Vice-presidente

Julio Pinto

Pontifícia Universidade Católica de Minas Gerais, Brasil

juliopinto@pucminas.br

Secretária-Geral

Ana Carolina Escosteguy

Pontifícia Universidade Católica do Rio Grande do Sul, Brasil

carolad@pucrs.br 